\title{
Feasibility and acceptability of a telephone-based chaplaincy intervention in a large, outpatient oncology center
}

\author{
Petra Sprik $^{1}$ (D) - Angela Janssen Keenan ${ }^{2} \cdot$ Danielle Boselli $^{3}$ (D) Sherri Cheeseboro ${ }^{2} \cdot$ Patrick Meadors $^{4}$ (D) \\ Daniel Grossoehme ${ }^{5}$ (i)
}

Received: 31 March 2020 / Accepted: 23 June 2020 / Published online: 4 July 2020

(C) Springer-Verlag GmbH Germany, part of Springer Nature 2020

\begin{abstract}
Purpose Telechaplaincy (the use of telecommunications and virtual technology to deliver spiritual and religious care by healthcare chaplains or other religious/spiritual leaders) is a relatively novel intervention that has increasingly been used in recent years, and especially during COVID-19. Telephone-based chaplaincy is one mode of telechaplaincy. The purpose of this study was to (1) describe telephone-based chaplaincy interventions delivered as the first point of contact to patients who screen positive for religious/spiritual concern(s) using an electronic data system, and (2) assess the feasibility and acceptability of delivering interventions in an outpatient cancer institute using this methodology.

Methods Patients were screened for religious and spiritual (R/S) concern(s) using an electronic data system. Patients indicating $\mathrm{R} / \mathrm{S}$ concern(s) were offered a telephone-based chaplaincy intervention and asked to complete a survey assessing acceptability of the intervention. Feasibility and acceptability data were collected.

Results Thirty percent of screened patients indicated R/S concern(s). Telephone-based chaplaincy interventions were offered to $100 \%$ of eligible patients, establishing contact with $61 \%$ of eligible patients, and offering chaplaincy interventions to $48 \%$ of those patients. Survey participants report high acceptability of the offered intervention.

Conclusion This is the first study examining feasibility and acceptability of telephone-based chaplaincy with oncology patients. Telephone-based chaplaincy is feasible and acceptable within an outpatient oncology setting, supporting the promise of this interventional strategy. Further research is needed to refine practices.
\end{abstract}

Keywords Telechaplaincy $\cdot$ Telehealth $\cdot$ Telephone $\cdot$ Chaplain $\cdot$ Spiritual care $\cdot$ Cancer

Petra Sprik

Petra.sprik@atriumhealth.org

1 Department of Supportive Oncology, Levine Cancer Institute, Charlotte, NC, USA

2 Spiritual Care and Education, Atrium Health, Charlotte, NC, USA

3 Department of Cancer Biostatistics, Levine Cancer Institute, Charlotte, NC, USA

4 Section of Psycho-Oncology, Department of Supportive Oncology, Assistant Professor of Medicine, Levine Cancer Institute, Charlotte NC, USA

5 Haslinger Family Pediatric Palliative Care Center, Rebecca D. Considine Research Institute, Akron Children's Hospital, Akron OH, USA

\section{Background}

It is estimated that in 20201.8 million people will be diagnosed with cancer in the USA [1] and that by 2026, 20.3 million cancer survivors will be in the USA [2]. In order to meet the needs of this large patient population and due to recent trends in healthcare, a large percentage of oncology care is delivered in outpatient settings [3]. Unfortunately, there are barriers that limit accessibility, efficiency, and effectiveness of delivering healthcare in outpatient settings. Two difficult barriers for supportive services to overcome are shorter, outpatient appointments in comparison with longer inpatient stays, which makes it more difficult to access the patient, and the cost of providing services in an outpatient setting $[4,5]$. Recently, COVID-19 has added an additional barrier to providing in-person services due to stay-at-home orders [6]. One approach to ameliorate these barriers is providing healthcare services via telehealth. 
The World Health Organization defines telehealth as "the use of telecommunications and virtual technology to deliver healthcare outside of traditional healthcare facilities" [7]. Telehealth modalities can include telephone, smartphone applications, live videoconferencing, and Internet interventions, which are delivered synchronously or asynchronously [8]. The terms "telehealth" and "telemedicine" are often used interchangeably; however, telehealth can include clinical and non-clinical services, where telemedicine only includes clinical services [7, 9].

Telehealth has been used since the early 1900s, grew exponentially in the 1970s with the growth of portable technology, is currently used by a wide variety of healthcare specialties, and is predicted to expand in its utilization [8-10]. At the 2017 annual meeting of the Association of Community Cancer Centers, Lindsay Conway predicted that by 2020, virtual consultation would increase by $60 \%$ among cancer care facilities [11]. COVID-19 drastically increased implementation of telehealth in the USA, with predicted long-term utilization of these modalities after the pandemic $[6,12]$.

Studies examining the impact of telehealth interventions have shown a variety of telehealth services to be feasible and acceptable, producing comparable outcomes to inperson care [9, 13-17]. However, not all aspects of telehealth services are acceptable to patients. A review by Cox and colleagues revealed a more nuanced impression of the acceptability of telehealth services by cancer survivors [4]. Cancer survivors reported the following benefits of telehealth services: enhanced management of one's care, anonymous space to talk about personal issues, increased time to address patient needs, convenience, and a sense of constant access and being monitored [4]. Reported negative perceptions of telehealth services included feeling like the service was an additional, burdensome responsibility, the format feeling impersonal, and limited technological literacy [4]. Similarly, a study on telehealth genetic counseling showed telehealth to be acceptable, except for some tasks which were difficult when performed distally [17]. When viewed together, these studies suggest that telehealth can be a feasible and acceptable way to meet patient's needs, but that telehealth may be more acceptable for certain interventions. More study is needed to understand the nuances of how to best deliver telehealth services.

Chaplaincy is one healthcare service that has more recently sought to refine its telehealth practices. Healthcare chaplains are individuals who work or volunteer within healthcare contexts to provide spiritual, religious, and emotional support to patients, caregivers, and staff [18]. Within inpatient settings, chaplaincy departments are often too small to meet all patients' spiritual, religious, and emotional needs [19]; the same is often true in outpatient clinics, with the added challenge of shorter appointments to meet patients. "Telechaplaincy," the use of telecommunications and virtual technology (which can include but is not limited to, telephone, smartphone applications, live videoconferencing and internet interventions) to deliver spiritual and religious care by healthcare chaplains or other religious/spiritual leaders, may serve as a promising delivery modality to reduce these barriers.

Forms of telechaplaincy have been used since the mid1900 s, with more formalized programs being developed in the early 2000s [20-23]. Recent studies have shown that telechaplaincy interventions are feasible and acceptable with caregivers of seriously ill patients, parents of children with cystic fibrosis, advanced illness/palliative care military veterans, and laypeople [21, 24-27]. Caregivers of seriously ill patients claimed that a telephone-based chaplaincy intervention helped them reflect and process and that they appreciated the anonymity of the phone [24]. Military veterans preferred an interdisciplinary telehealth program which included chaplaincy to similar in-person care [21]. Existing studies report positive outcomes of telephone-based chaplaincy interventions, including reduced levels of spiritual struggle and enhanced spiritual well-being $[25,26]$. It appears that telechaplaincy is a potentially efficacious method for providing chaplaincy in an outpatient setting, with most research being done on telephone-based chaplaincy interventions.

However, there are gaps in understanding the feasibility, acceptability, and outcomes of telechaplaincy. To date, research is limited to telechaplaincy interventions delivered as scheduled interventions. To our knowledge, no studies exist on the feasibility and acceptability of telechaplaincy interventions where the intervention is delivered as the first point of contact. Additionally, only one study examines telephonebased chaplaincy with outpatient oncology patients, and it does not address feasibility and acceptability [27]. Chaplains may also experience additional barriers to delivering telechaplaincy. A previous study found that patients may associate chaplains with death and fear a visit from the chaplain [28]. Additionally, physical presence is central to chaplaincy interventions [28, 29]. Little is known about how these variables affect the acceptability of telechaplaincy.

The purpose of this study was to describe a telephonebased chaplaincy intervention delivered as the first point of contact and assess the feasibility and acceptability of delivering interventions in an outpatient cancer institute using this methodology.

\section{Methods}

\section{Participants}

This study was conducted at headquarters of an academic, hybrid, multi-site, community-based cancer institute in the Southeastern United States. The study was approved by the institutional review board (IRB\# 01-19-36E). Participants were eligible if they were over the age of 18, English- 
speaking, and screened positive for religious or spiritual (R/S) concern(s) using an electronic data system. The use of the electronic data system to direct services was approved by the institutional review board prior to this study and permission extended to this study (IRB\# 04-18-09E). Participants may or may not have had previous interaction with the chaplain by phone or in-person.

\section{Procedure}

As standard clinical practice at the cancer institute, from March 18, 2019, to April 26, 2019, all patients consulted in surgical oncology, medical oncology, supportive oncology, or radiation oncology simulation were asked by a clinic staff member to complete a distress screening assessment on a tablet prior to their appointment. Screening questions included psychological, financial, social, and religious/spiritual (R/S) queries and were used to generate referrals to supportive care services, including chaplaincy. Two questions evaluated R/S concern: (1) Do you have spiritual or religious concerns? (response yes or no) and (2) Select any of the following emotional/spiritual concerns you are experiencing: struggle to find meaning/ hope in life, doubts about your faith, concern for family, isolation, shame/guilt, fear of death (answers were eligible for multi-selection). Each variable correlates with one or more of Galek and colleague's seven spiritual need constructs [30]. Any patient who indicated one or more R/S concerns was referred to a chaplain. This procedure was previously approved by the IRB and implemented as standard of care.

Prior to this study, as part of clinical practice, chaplains reached out to patients who screened positive for R/S concern(s) either by telephone or in-person. For the purposes of this study, all visits were conducted by telephone using a systematized procedure in order to assess the feasibility and acceptability of this modality. Two chaplains delivered interventions; one was a board-certified chaplain and one pursuing board certification. An online random number generator determined which chaplain would provide the intervention for the first listed patient, with subsequent alternating assignment.

Prior to delivering the intervention, the chaplain reviewed the patient chart to asses medical condition and previous interaction with supportive services, in order to more sensitively engage in the conversation. The intervention was a semistructured phone call using a script, which was based on previous chaplaincy interactions, but standardized for study use (see Appendix 1). The intervention aimed to introduce the patient to the chaplain, address the indicated $\mathrm{R} / \mathrm{S}$ concern(s) from the screener, address any additional R/S concerns identified on the phone call, and establish follow-up visits if appropriate. Due to limitations in the chaplains' available clinical hours, only one phone call was made to each person who screened positive for $\mathrm{R} / \mathrm{S}$ concern(s), leaving a voicemail if possible/permissible when contact was not made. The intervention was delivered four to 12 days after the initial assessment, based on how quickly the referral report could be generated and chaplains' availability to make the calls during clinical hours.

At the conclusion of the intervention, the chaplain requested permission to email the patient an anonymous survey analyzing acceptability of the intervention. If the patient agreed, a survey was sent via email within $48 \mathrm{~h}$ using an automated email system, which sent the survey up to three times if not completed. Consent was explained at the beginning of the survey, and completion of the survey was considered consent, as deemed by the IRB.

\section{Measures}

\section{Demographics}

Demographics including age, gender, and race were obtained from the distress screener on all patients who completed the assessment (including those who screened positive and negative for R/S concerns). Patient characteristics, including age, gender, race, religion (eligible for multi-select), and whether cancer diagnosis had been received at time of phone call, were obtained from completed surveys.

\section{Feasibility}

Collected feasibility data included (1) the percentage of patients eligible for an intervention who received a phone call from a chaplain, (2) the percentage of contacted patients who talked with a chaplain on the phone, and (3) the percentage of patients who talked with a chaplain on the phone who received a R/S intervention.

For the first and second feasibility data points, chaplains recorded whether they were able to talk with the patient on the phone, left a voicemail, delivered a message to family, or received a call back. For the third feasibility data point, chaplains determined whether they had delivered an R/S intervention by phone based on criteria related to whether the call relied upon chaplain training and expertise (see Appendix 2).

\section{Acceptability}

Acceptability data was obtained from surveys completed by participants who received an intervention and agreed to be sent the survey. Survey questions were Likert-scale questions, adapted from previous chaplaincy patient satisfaction and effectiveness surveys [30-34]. 


\section{Intervention description}

To understand the patient's perception of the intervention, surveys included questions on the patient's perception of the length and subject matter of the intervention.

\section{Statistical procedures}

Characteristics of all subjects completing the distress screening and the subset completing the survey were summarized with descriptive statistics. To understand the representativeness of subjects offered an intervention in the context of this study to the epidemiology of the cancer institute and the representativeness of subjects completing a survey of those eligible for a intervention, characteristics were compared with Fisher's exact and rank-sum tests (where appropriate) between the following subsets of subjects, respectively:

(a) Subjects indicating at least one $\mathrm{R} / \mathrm{S}$ concern on the distress screening v. subjects not indicating an R/S concern on the distress screening

(b) Subjects completing the survey versus subjects indicating at least one R/S concern on the distress screening.
Descriptive statistics were used to summarize survey responses to assess feasibility and acceptability of the intervention. All analyses were conducted using SAS 9.4 (SAS Institute, Cary, NC).

\section{Results}

\section{Demographics}

A total of 711 unique patients completed the distress screening, of whom $30 \%$ indicated at least one $\mathrm{R} / \mathrm{S}$ concern and were eligible for the intervention. Of those who talked to a chaplain on the phone, $33 \%$ completed the survey (see Fig. 1).

Patient characteristics of sub-groups are shown in Table 1. Subjects indicating at least one $\mathrm{R} / \mathrm{S}$ concern were younger ( $p=.021$ ) than those not indicating $\mathrm{R} / \mathrm{S}$ concern(s), but evidence did not suggest distributional differences in gender ( $p=.173)$ or race $(p=.160)$ between the subsets.

Additionally, no distributional differences in age $(p=.817)$, gender $(p>.999)$, or race $(p=.531)$ were detected between participants indicating at least one R/S concern and survey respondents.
Fig. 1 Consort statement (created using Microsoft Word)

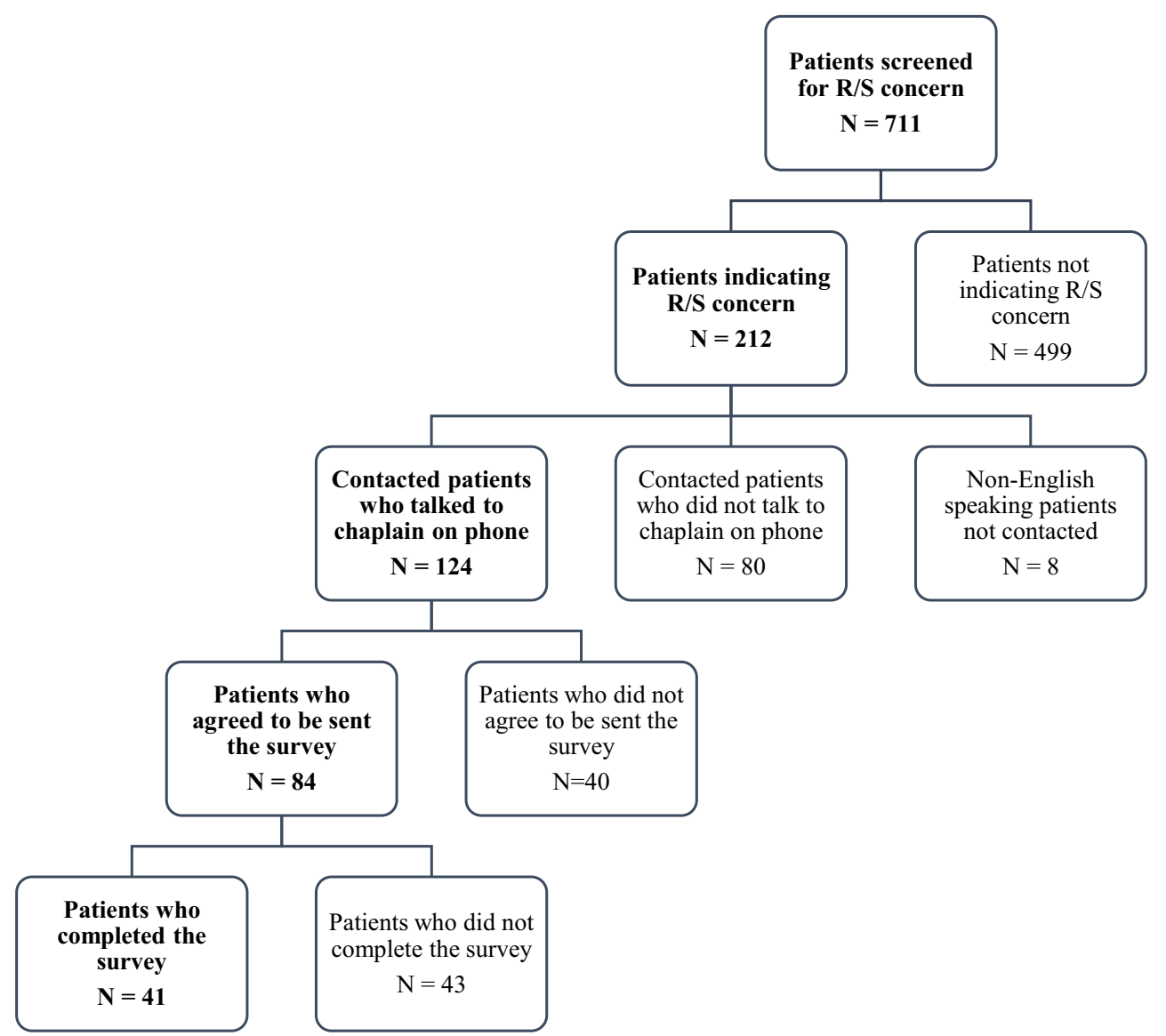


Table 1 Patient characteristics of study sub-groups

\begin{tabular}{|c|c|c|c|}
\hline & $\begin{array}{l}\text { Patients indicating no } \\
\mathrm{R} / \mathrm{S} \text { concern }(n=499)\end{array}$ & $\begin{array}{l}\text { Patients indicating } \\
\mathrm{R} / \mathrm{S} \text { concern }(\mathrm{s})(n=212)\end{array}$ & Survey respondents $(n=41)$ \\
\hline Variable & Median [min, max] & Median [min, max] & Median [min, max] \\
\hline \multirow[t]{2}{*}{ Age at assessment } & $61[18,90]$ & $57.5[19,91]$ & $57[27,74]$ \\
\hline & Frequency $(\%)$ & Frequency $(\%)$ & Frequency $(\%)$ \\
\hline \multicolumn{4}{|l|}{ Gender } \\
\hline Female & $308(62)$ & $143(67)$ & $26(63)$ \\
\hline Male & $190(38)$ & $69(33)$ & $13(32)$ \\
\hline Unknown/prefer not to answer & $0(0)$ & $0(0)$ & $1(2)$ \\
\hline Missing & $1(0)$ & $0(0)$ & $1(2)$ \\
\hline \multicolumn{4}{|l|}{ Race } \\
\hline American Indian or Alaska Native & $2(0)$ & $3(1)$ & $0(0)$ \\
\hline Asian & $7(1)$ & $5(2)$ & $2(5)$ \\
\hline Black or African American & $112(22)$ & $36(17)$ & $5(12)$ \\
\hline White & $365(73)$ & $149(70)$ & $30(73)$ \\
\hline Other, unknown or prefer not to answer & $13(3)$ & $19(9)$ & $4(10)$ \\
\hline \multicolumn{4}{|l|}{ Religion (multi-select available) } \\
\hline Agnostic & Not captured in assessment & & $1(2)$ \\
\hline Christian (non-denominational) & & & $14(34)$ \\
\hline Christian (Protestant) & & & $13(32)$ \\
\hline Christian (Catholic) & & & $5(12)$ \\
\hline Hindu & & & $1(2)$ \\
\hline Jewish & & & $2(5)$ \\
\hline None & & & $1(2)$ \\
\hline Spiritual but not religious & & & $6(15)$ \\
\hline Cancer diagnosis received at time of call & Not captured in assessment & & \\
\hline Yes & & & $32(78)$ \\
\hline No & & & $8(20)$ \\
\hline Missing & & & $1(2)$ \\
\hline
\end{tabular}

Note: Percentages do not sum to $100 \%$ for prompts designed for multi-select and due to rounding

\section{Feasibility}

A total of 208 participants were eligible to receive an intervention; $100 \%$ received a phone call from a chaplain. Chaplains made most phone calls within pre-planned time blocks. Seldomly, chaplains rearranged clinical responsibilities to contact patients when the patient was not at medical appointments.

Of the 204 patients contacted, $61 \%$ of patients talked to a chaplain on the phone, either answering the first call $(n=118)$, answering the first call and rescheduling a second call due to bad timing $(n=2)$, or calling the chaplain back after an initial voicemail $(n=4)$. If the subject was unable to talk on the phone at time of contact, the reason was obtained conversationally from family answering the phone in lieu of the patient or by the patient on a later call; reasons included feeling too sick to answer the phone, being at a medical appointment, having a medical reason they are unable to talk or hear on the phone (such as a tracheostomy or deafness), not having enough minutes programmed on their phone, being busy, or family denying permission to talk to the patient.

Chaplains spoke to 124 patients on the phone, delivering $\mathrm{R} /$ $\mathrm{S}$ interventions to $48 \%(n=60)$. In cases where chaplains did not deliver R/S interventions, they had supportive conversations that did not require chaplain expertise, had patients deny $\mathrm{R} / \mathrm{S}$ concern(s), had patients refuse the conversation, or were unable to deepen the conversation.

\section{Acceptability}

Acceptability with the telephone-based chaplaincy intervention was high among survey respondents. Participants' positively ranked the chaplain's ability to deliver service components over the phone. Over $90 \%$ of surveyed participants were "very satisfied" with the chaplain's ability to listen to them, and to make them feel comfortable on the phone. Over half were "very satisfied" with the chaplain's ability to pray, help 
them tap into their inner strengths and resources, and overcome their fears and concerns on the phone (see Fig. 2).

The majority of survey participants found various aspects of the intervention to be acceptable, indicating they were "very much" satisfied with the length of the phone call, the chaplain's conveyed care, and response to spiritual and emotional concerns. The majority of participants were "not at all" scared by receiving a phone call from a chaplain, with $24 \%$ indicated some level of fear (see Fig. 3).

Only five participants indicated "not at all" or "slightly" to questions pertaining to acceptability of the intervention. These people varied by gender, age, race, and the topics that they discussed on the phone with the chaplain. Most spent less than $10 \mathrm{~min}$ on the phone with the chaplain $(n=4)$, with one spending between 11 and $30 \mathrm{~min}$. They indicated moderate or high satisfaction to most other questions.

After having experienced the telephone-based chaplaincy intervention, survey participants were asked how they would prefer to receive chaplain interventions from a list of options available for multi-select. The most commonly indicated medium was the telephone $(n=30)$. The next most commonly indicated were in-person at a doctor's appointment $(n=11)$, in-person by scheduling a chaplain visit $(n=10)$, and by text $(n=7)$.

\section{Telephone-based chaplaincy intervention}

According to survey respondents, the majority of telephone conversations lasted less than $30 \mathrm{~min}$; with categorical survey options being less than $10 \min (n=12)$, between 11 and $30 \min (n=19)$, between $31 \mathrm{~min}$ and an hour $(n=2)$, and more than an hour $(n=1)$. Seven people did not remember the length of the conversation.

Survey respondents also identified their perception of the subject matter of the intervention. Frequencies of addressed R/ $\mathrm{S}$ concern(s) were similar to frequencies of experienced R/S concern(s) among the surveyed population. The most frequently addressed subject matter was concern for family, fear of death, and spiritual/religious concern. However, more participants reported talking to a chaplain about religious and spiritual subject matter and isolation than reported experiencing those concerns. A few patients reported experiencing concern for family, shame/ guilt, and fear of death that did not report talking about those R/S concerns in the intervention (see Table 2).

\section{Discussion}

These results suggest that screening for R/S needs using an electronic data system and using phone calls as the first point of contact for offering interventions is feasible at an outpatient cancer institute. Two chaplains who were working part-time were able to complete all referrals in a timely manner, establishing contact with 124 patients, and delivering chaplaincy interventions to 60 patients over the course of 6 weeks. While rearranging clinical time was required, this need was minimal.

Findings also suggest that chaplaincy delivered by phone as the first contact is acceptable to patients seen in an outpatient oncology clinic, with surveyed patients reporting positive responses about the chaplain's abilities on the phone, and various aspects of the service offered. These findings are
Fig. 2 Acceptability of chaplain's abilities of delivering telephonebased chaplaincy. Note:

Percentages may not sum to $100 \%$ due to rounding (created using Microsoft Excel)
How satisfied were you with the chaplain's ability (on the phone) to provide a referral for other help you needed?

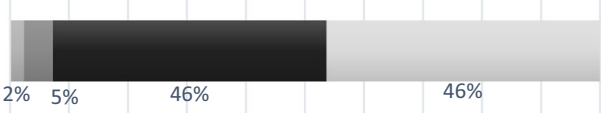

How satisfied were you with the chaplain's ability (on the phone) to help you overcome your fears or concerns?

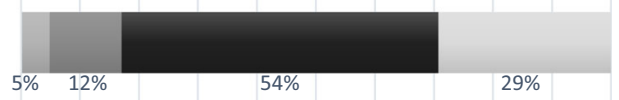

How satisfied were you with the chaplain's ability (on the phone) to help you tap into your inner strengths and resources?

How satisfied were you with the chaplain's ability to pray with you on the phone?

How satisfied were you with the chaplain's ability to make you feel comfortable on the phone?

How satisfied were you with the chaplain's ability to really listen to you on the phone?
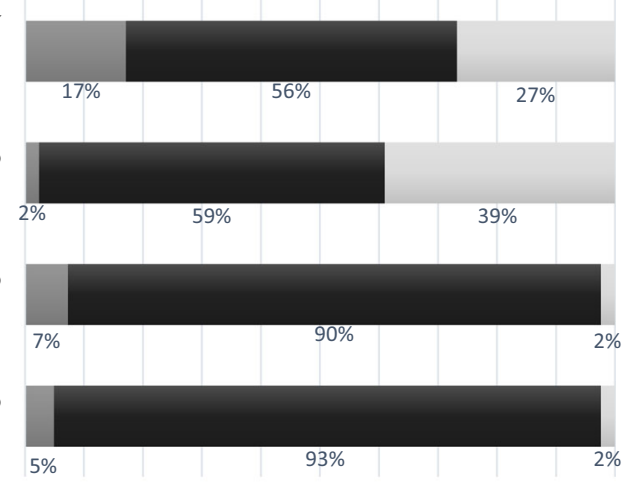

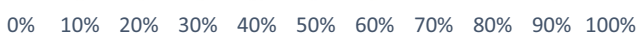
$\%$ of Survey Participants

\lightly $\square$ Moderately $\quad$ Very Satisfied $\square$ Does not apply 
Fig. 3 Acceptability of telephone-based chaplaincy intervention. Note: Percentages may not sum to $100 \%$ due to missing responses $(2 \%)$ being excluded from charts and due to rounding
Did receiving a phone call with the chaplain scare you?

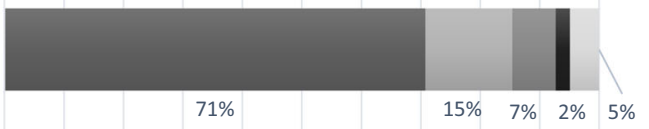

Did the phone call with the chaplain provide enough privacy for you to feel comfortable talking?

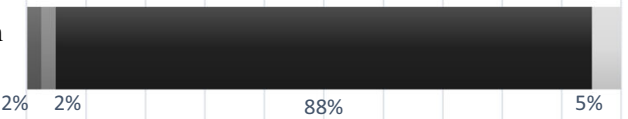

On the phone, did the chaplain help you use your faith, beliefs or values to cope?

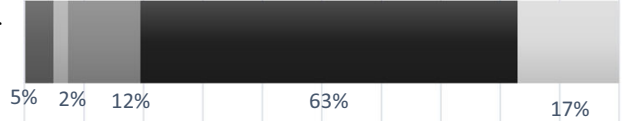

On the phone did the chaplain seem to care about you?

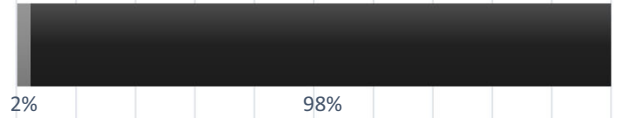

Did the chaplain spend enough time with you on the phone?

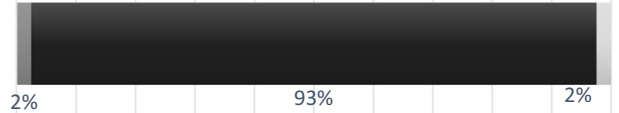

How well did the chaplain respond to your spiritual and emotional concerns on the phone?

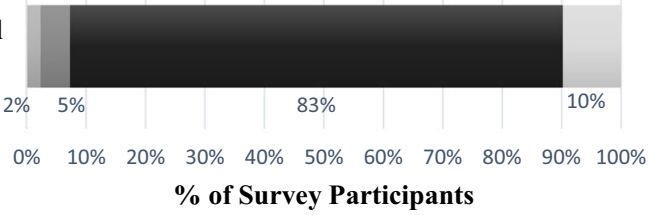

Not at all $\square$ Slightly $\square$ Moderately $\quad$ Very Much $\square$ Does not apply similar to other telechaplaincy acceptability studies, which reported telechaplaincy as an acceptable intervention among various populations [20-23]. The intervention also has similar acceptability to a study examining acceptability of inpatient chaplain interventions [30].

Findings also suggest that the phone may be a preferred mode of contact for outpatient oncology patients. Survey respondents most often indicated that phone was their preferred method of receiving chaplaincy. This response is biased by the telephone being the mode by which they recently received chaplaincy services; however, it shows acceptability of the service delivered and the potential for this being a preferred method.

Nonetheless, findings also suggest that there are ways to improve this intervention. This intervention differed from previously studied interventions in that patients did not enroll in a telechaplaincy program prior to receiving contact from the chaplain by telephone. Approximately $25 \%$ of patients were at least "slightly" scared by receiving a phone call from the chaplain, despite being informed on the screener that they may be contacted by a member of the supportive oncology team, and the chaplain introducing themselves as "from the spiritual care department" rather than as a chaplain. While patient's fear did not deter higher acceptability scores with the intervention overall, it does suggest that fear of receiving a call from the chaplain is a necessary barrier to address in order to deliver telephone interventions in a less distressing way.

This intervention was also different from previous telechaplaincy interventions in that it did not have an anticipated length of conversations. Surveyed patients reported short phone conversation lengths, with most lasting less than $30 \mathrm{~min}$. This was much shorter than other interventions which offered multiple, hour-long conversations [24, 25]. Nonetheless, patients found the care they received acceptable. This suggests that telephone-based chaplaincy might be a timely way to establish contact and assess for deeper needs that may require further follow-up. However, short conversations likely do not provide enough time to deeply assess or address patient's R/S concern(s), as is shown by varied responses to the question "on the phone, did the chaplain help you use your faith, beliefs or values to cope?" In comparison, longer interventions, like the one delivered by Betz and colleagues, showed evidence that spiritual struggle was addressed in a longer, multi-meeting telephone intervention [25]. Future studies should address the ideal timing and length of telechaplaincy interventions.

Findings also suggest that a wide range of $\mathrm{R} / \mathrm{S}$ concerns can be addressed via telephone. Concern for family, fear of death and R/S concerns were the most commonly identified 
Table 2 Survey respondents report of R/S concern(s) and telephone intervention subject matter $(n=41)$

\begin{tabular}{lll}
\hline $\begin{array}{l}\text { R/S concern (multi- } \\
\text { select available) }\end{array}$ & $\begin{array}{l}\mathrm{R} / \mathrm{S} \text { concern(s) } \\
\text { experienced in last } \\
7 \text { days, frequency }(\%)\end{array}$ & $\begin{array}{l}\mathrm{R} / \mathrm{S} \text { concern(s) } \\
\text { discussed in telephone } \\
\text { intervention, } \\
\text { frequency }(\%)\end{array}$ \\
\hline $\begin{array}{l}\text { Concern for family } \\
\text { Fear of death }\end{array}$ & $24(59)$ & $23(56)$ \\
$\begin{array}{l}\text { Religious/spiritual } \\
\text { concerns }\end{array}$ & $4(10)$ & $9(22)$ \\
$\begin{array}{l}\text { Isolation } \\
\begin{array}{l}\text { Struggle to find } \\
\text { meaning/hope }\end{array}\end{array}$ & $4(10)$ & $9(22)$ \\
$\begin{array}{l}\text { Shame/guilt } \\
\text { Doubts about } \\
\text { your faith }\end{array}$ & $3(7)$ & $6(15)$ \\
None of listed & $2(5)$ & $4(10)$ \\
concerns & $11(27)$ & $2(5)$ \\
Do not remember & N/A & $2(5)$ \\
\hline
\end{tabular}

Note: Percentages do not sum to $100 \%$ as prompts were eligible for multiselect

subject matter by patients, though patients indicated high acceptability with conversations covering all indicated R/S concerns. At the same time, there were several times where the chaplain did not address the patient's reported R/S concern, including concern for family, shame/guilt, and fear of death. This may be because of the sensitive nature of the subject matter, chaplain skill, or the limitations of the telephone. More study is needed to determine which $\mathrm{R} / \mathrm{S}$ concerns are best addressed by telehealth versus in-person chaplaincy.

\section{Limitations and strengths}

There were several limitations of this study. Small sample size limits the generalizability of the study, and ability to examine correlations. Participants came from a single site, where the R/ $\mathrm{S}$ demographic is significantly different from national means, which also limits generalizability. Resource limitations permitted only a single contact by the chaplain, whether it was a voicemail or an actual conversation. Responses were obtained through self-reported quantitative surveys, and it was not possible to obtain a more in-depth understanding of why participants responded as they did.

The strengths of this study include being the first study examining acceptability and feasibility of telephone-based chaplaincy within an outpatient oncology setting. The demographics of the surveyed population being similar to the population offered the intervention is also a strength. Two chaplains delivering the intervention enhanced generalizability by avoiding outcomes due to a single chaplain's style. Anonymous surveys minimized pressure to provide socially desirable response.

\section{Conclusion}

This study adds to the emerging voice that supports telephone-based chaplaincy as an acceptable and feasible methodology. Especially in oncology, where healthcare is increasingly being delivered in outpatient settings, telechaplaincy offers a promising way to overcome the difficulty of addressing patient's R/S concerns within the short time span of patient appointments. This methodology is also relevant due to COVID-19. As telechaplaincy practice is refined through research, it may prove to be an essential tool in addressing oncology patients' holistic health.

Acknowledgments This project was supported in part by Transforming Chaplaincy, to whom we extend our deepest thanks. We would like to thank the Levine Cancer Institute Department of Supportive Oncology for their support and Dr. Declan Walsh for reviewing the manuscript.

Authors' contributions All authors made substantial contributions to the conception, design, and analysis of the work. Data collection was performed by Petra Sprik and Sherri Cheeseboro. The first draft of the manuscript was written by Petra Sprik and all authors commented on previous versions of the manuscript; revisions were made by all authors. All authors approved the manuscript to be published and are accountable for aspects of the work.

Funding information This study was funded in part by Transforming Chaplaincy through a grant bestowed by the John Templeton Foundation (57029).

Data availability Authors have full control of primary data and will allow the journal to review de-identified data upon request.

\section{Compliance with ethical standards}

Conflicts of interest/competing interests Petra Sprik, Angela Janssen Keenan, Danielle Boselli, Sherri Cheeseboro, Patrick Meadors and Daniel Grossoehme declare that this study was partially funded by a grant from Transforming Chaplaincy. Authors have no other conflicts of interest to declare.

Ethics approval All procedures performed in studies involving human participants were in accordance with the ethical standards of the institutional research committee (IRB\# 04-18-09E and IRB\# 01-19-36E) and with the 1964 Helsinki declaration and its later amendments or comparable ethical standards.

Consent to participate Distress screenings and the use of findings from the screening were approved through a prior Institutional Review Board review. Completion of the survey was considered informed consent for this study, as deemed by the Institutional Review Board. An explanation of the study, risks, and benefits was provided to each person prior to the survey. 


\section{Appendix 1. Telephone script}

Hello, is this [name]?

If not the patient, and leaving a message on voicemail or with a family member

Hello. My name is [name]. I'm from the Spiritual Care Department at [Institution] and am calling for [patient's name]. This is a non-urgent call, but I would love to talk with you whenever you get a chance. Whenever is convenient for you, please call me back at [number]. Again, my name is [name] and my phone number is [number].

ONLY if the person confirms their identity

Hello [name]. My name is [name]. I'm from the Spiritual Care Department at [Institution]. I do not have any medical or urgent news. I am simply calling to follow up after your appointment. How is everything going?

If this lead to conversation/pastoral interventions, proceed with conversation.

I wanted to introduce myself. As I said, I'm [name] and we recognize that health appointments can be stressful and affect you spiritually and emotionally as well as physically. As a chaplain, I provide support for patients of any faith, no faith and everything in between. I know you recently had an appointment, and just wanted to touch base to see if anything has been particularly challenging for you lately.

If this leads to conversation/pastoral interventions, proceed with conversation.

[If you have not talked about the indicated need yet]

I'd like to ask you one more thing. Do you remember filling out a survey on a tablet when you were in for your appointment?

If Yes:

One of the questions on that survey asked about spiritual and emotional struggles you are experiencing and you marked $[R / S$ concern(s) indicated $]$. Is that something you are still dealing with?

If this leads to conversation/pastoral interventions, proceed with conversation.

If No:

There's a lot going on at appointments. It can be easy to forget a small detail like that. It was a survey on an iPad with many questions. One question was about spiritual and emotional struggles and you marked $[R / S$ concern(s) indicated $]$. Is that something you are still dealing with?

If this leads to conversation/pastoral interventions, proceed with conversation.

[If a follow up appointment seems appropriate]

We have talked about some pretty important things today. I would love to follow up with you later. Would that be okay with you? Is there a time that we could meet in person or talk on the phone again?

There is one last thing that I wanted to ask before we wrapup. We are trying to improve our Spiritual Care and would love your feedback on this call for a research project. Would you be willing to fill out a quick email survey if we send it to you? It will be confidential and only take about 10 to $15 \mathrm{~min}$.

\section{If Yes:}

Can I get your email address?

Thank you for talking with me today and please know that Spiritual Care is available to you whenever you might need it. You can reach me by calling [institution] and asking for the chaplain, or by asking for me during one of your visits.

\section{Appendix 2. Telephone script}

\section{$R / S$ interventions include:}

- Talking with patient about religious/spiritual need identified on survey

- Performing religious rite or ritual

- Prayer

- Scripture reading

- Blessing

- Other ritual

- Asking guided questions/discussion to facilitate greater understanding of:

- Religion/Spirituality

- Current life/health situation

- Emotional/Religious/Spiritual response to a difficult experience

- Decision making about healthcare, life choices, etc.

- Cultural and religious values

- Purpose/life review

- End-of-life or death

- Feelings around treatment, life circumstances or religion/ spirituality

- Supportive or broken relationships

- Coping mechanisms

- Patient's limitations or strengths

- Grief responses

- Crisis responses

- Facilitate

- Preparation for the end of life

- Preparation for treatment (i.e. - coping mechanisms for treatment)

- Connection to grief resources

- Incorporating religious/spiritual needs into care plan

- Connection with a spiritual group

- Communication between support network

- End-of-life resources such as advanced directives, etc. 


\section{$R / S$ interventions do not include:}

- A surface level conversation or "shooting the breeze"

- Patient admits to having a R/S concern but does not explore that need with the chaplain

- Patient denies conversation

- Chaplain provides a referral to other services

- Patient names their religion, but does not describe significance

- Chaplain only orients patient to pastoral care services

- Supportive conversation that does not include deeper meaning-making

\section{References}

1. American Cancer Society (2019) Cancer facts and figures 2020 . American Cancer Society, Atlanta https://www.cancer.org/ research/cancer-facts-statistics/all-cancer-facts-figures/cancerfacts-figures-2020.html. Accessed 31 March 2020

2. National Institute of Health (2018) Cancer statistics. U.S. Department of Health and Human Services. https://www.cancer. gov/about-cancer/understanding/statistics. Accessed 14 Jan 2020

3. Williamson TS (2008) The shift of oncology inpatient care to outpatient care: the challenge of retaining expert oncology nurses. Clin J Oncol Nurs 12(1):186-189

4. Cox A, Lucas G, Marcu A, Piano M, Grosvenor W, Mold F, Maguire R, Ream E (2017) Cancer survivors' experience with telehealth: a systematic review and thematic synthesis. J Med Internet Res 19(1):e11

5. Holland J, Watson M, Dunn J (2011) The IPOS new international standard of quality cancer care: integrating the psychosocial domain into routine care. Psycho-Oncology 20:677-680

6. Wosik J, Fudim M, Cameron B, Gellad ZF, Cho A, Phinney D, Curtis S, Roman M, Poon EG, Ferranti J, Katz JN, Tcheng J (2020) Telehealth transformation: COVID-19 and the rise of virtual care. $\mathrm{J}$ Am Med Inform Assoc (online)

7. World Health Organization (2020) Telehealth. World Health Organization. https://www.who.int/sustainable-development/ health-sector/strategies/telehealth/en/. Accessed 14 Jan 2020

8. Mahar JH, Rosencrance GJ, Rasmussen PA (2018) Telemedicine: past, present and future. Cleve Clin J Med 85(12):938-942

9. Larson JL, Rosen AB, Wilson FA (2018) The effect of telehealth interventions on quality of life of cancer patients: a systematic review and meta-analysis. Telemed J E Health 24(6):397-405

10. Sirintrapun SJ, Lopez AM (2018). Telemedicine in cancer care. Memorial Sloan Kettering Cancer Center, New York, NY. Ascopubs.org. Accessed 25 Dec 2019,

11. Zaleski A (2017) 5 healthcare trends impacting cancer care. Medcity News. https://medcitynews.com/2017/03/5-healthcaretrends-impacting-cancer-care/?rf $=1$. Accessed 14 Jan 2020

12. Lewis GD, Hatch SS, Widerhold LR, Swanson TA (2020) Longterm institutional experience with telemedicine services for radiation oncology" a potential model for long-term utilization. Adv Radiat Onc (online)
13. Kruse CS, Krowski N, Rodriguez B, Tran L, Vela J, Brooks M (2017) Telehealth and patient satisfaction: a systematic review and narrative analysis. BMJ Open 7:e016242

14. Chen YY, Guan BS, Li ZK, Li XY (2017) Effect of telehealth intervention on breast cancer patients' quality of life and psychological outcomes: a meta-analysis. J Telemed Telecare 24(3):157167

15. Mistry N, Keepanasseril A, Wilczynski NL, Nieuwlaat R, Ravall M, Haynes RB, the Patient Adherence Review Team (2015) Technology-mediated interventions for enhancing medication adherence. J Am Med Inform Assoc 22(e1):e177-e193

16. Salmoiraghi A, Hussain S (2015) A systematic review of the use of telepsychiatry in acute settings. J Psychiatr Pract 21(5):389-393. https://doi.org/10.1097/PRA.0000000000000103

17. Platten U, Rantala J, Lindblom A, Brandberg Y, Lindgren G, Arver B (2012) The use of telephone in genetic counseling versus inperson counseling: a randomized study on counselees' outcome. Familial Cancer 11:371-379

18. Timmins F, Caldeira S, Maryanne M, Pujol N, Sheaf G, Weathers E, Whelan J, Flanagan B (2018) The role of the healthcare chaplain: a literature review. J Health Care Chaplain 24(3):87-106

19. Fitchett G, Peterr MM, Burton LA (2000) Spiritual care in the hospital: who requests it? Who needs it? J Pastoral Care 54(2): 173-186

20. U.S. Department of Veterans Affairs (2020) History of VA chaplaincy. https://www.patientcare.va.gov/chaplain/History_of_VA Chaplaincy.asp

21. Maudlin J, Keene J, Kobb R (2006) A road map for the last journey: home telehealth for holistic end-of-life care. Am J Hosp Palliat Med 23(5):399-403

22. Strano, A. (2014) Telechaplaincy: personal (but not in-person) spiritual care. Vision (Nov-Dec 2014)

23. VA NW Health Network (2013) 2013 VISN 20 Annual Report. https://www.visn20.med.va.gov/VISN20/AnnualReports/ 2013VISN20AnnualReport.pdf. Accessed 3 June 2020

24. Steinhauser KE, Olsen A, Johnson K, Sanders LL, Olsen M, Ammarell N, Grossoehme D (2016) The feasibility and acceptability of a chaplain-led intervention for caregivers of seriously ill patients: a caregiver outlook pilot study. Palliat Support Care 14(5): 456-467

25. Betz J, Szczesniak R, Lewis K, Pestian T, Bennethum AS, McBride J, Grossoehme DH (2019) Feasibility and acceptability of a telephone-based chaplaincy intervention to decrease parental spiritual struggle. J Relig Health 58(6):2065-2085

26. Zwart LM, Palmer SL, Strawn BD, Milliron JT, Brown WS (2000) The impact of lay pastoral telecare on the spiritual well-being of church attenders. J Pastoral Care 54(1):63-73

27. Sprik PJ, Walsh K, Boselli DM, Meadors P (2019) Using patientreported religious/spiritual concerns to identify patients who accept chaplain interventions in an outpatient oncology setting. Support Care Cancer 27(5):1861-1869

28. McCormick SC, Hildebrand AA (2015) A qualitative study of patient and family perceptions of chaplain presence during posttrauma care. J Health Care Chaplain 21:60-75

29. Massey K, Barnes MJD, Villines D, Goldstein JD, Hisey Pierson ALH, Scherer C, Vander Laan B, Thomas Summerfelt WM (2015) What do I do? Developing a taxonomy of chaplaincy activities and interventions for spiritual care in intensive care unit palliative care. BMC Palliat Care 14(10) 
30. Galek K, Flannelly KJ, Vane A, Galek RM (2005) Assessing a patient's spiritual needs: a comprehensive instrument. Holist Nurs Pract 19(2):62-69

31. Flannelly KJ, Galek K, Tannenbaum HP, Handzo GF (2007) A preliminary proposal for a scale to measure the effectiveness of pastoral care with family members of hospitalized patients. J Pastoral Care Counsel 61(1-2):19-29

32. Flannelly KJ, Oettinger M, Galek K, Braun-Storck A, Kreger R (2009) The correlates of chaplains' effectiveness in meeting the spiritual/religious and emotional needs of patients. J Pastoral Care Counsel 63(1-2):1-16
33. Vandecreek L (2004) How satisfied are patients with the ministry of chaplains? J Pastoral Care Counsel 58(4):335-342

34. Snowden A, Telfer I (2017) Patient reported outcome measure of spiritual care as delivered by chaplains. J Health Care Chaplain 0:125

Publisher's note Springer Nature remains neutral with regard to jurisdictional claims in published maps and institutional affiliations. 